\title{
Preservação de documentos arquivísticos digitais: reflexões sobre as estratégias de encapsulamento
}

\author{
Preservation of digital archival documents: reflections on the \\ strategies of encapsulation
}

\author{
Daniel Flores* \\ Henrique Machado dos Santos **
}

\section{RESUMO}

Os constantes avanços das tecnologias da informação ocasionaram mudanças no que tange à gênese do documento arquivístico, considerado objeto de estudo da arquivologia. Com o surgimento do documento arquivístico digital, houve a necessidade de atualizar as teorias, de forma a contemplar a realidade digital. Surgiram novas abordagens, como a preservação digital, que utiliza procedimentos estruturais e operacionais para preservar os documentos digitais. Este artigo tem por objetivo realizar uma reflexão sobre as estratégias de encapsulamento, discutindo a sua aplicabilidade nos acervos, bem como o seu uso em conjunto com outras estratégias. O método para realizar esta reflexão consiste no levantamento bibliográfico de materiais previamente publicados. Dessa forma, os dados coletados são analisados de forma qualitativa. Este estudo realça as vantagens e desvantagens das estratégias de encapsulamento, apontando lacunas que poderão ser solucionadas com o auxílio de outras estratégias de preservação digital. Por fim, enfatiza-se uma maior aproximação das atividades de

\begin{abstract}
Constant advances in information technology have led to changes regarding the genesis of the archival document, considered the object of study of archival science. With the emergence of the digital archival document, it was necessary to update theories to contemplate digital reality. New approaches have emerged, such as digital preservation, which uses structural and operational procedures to preserve digital documents. This article aims to carry out a study of encapsulation strategies, discussing their applicability in the collections, as well as its use in conjunction with other strategies. The method adopted here is a survey of previously published literature on the issue. Thus, the data collected is analyzed qualitatively. This study highlights the advantages and disadvantages of the strategies of encapsulation, pointing out gaps which could be resolved with the help of other strategies of digital preservation. Finally, it emphasizes greater approximation between activities of digital preservation and knowledge management, an issue that is little discussed in the context of preservation of digital archival documents.
\end{abstract}

\footnotetext{
* Doutor em Metodologías y Líneas de Investigación en Biblioteconomía y Documentación pela Universidad de Salamanca/España. Professor adjunto do Departamento de Documentação da Universidade Federal de Santa Maria. Endereço: Av. Roraima, 1.000, prédio 74, Sala 2.157, Camobi, CEP 97105-900, Santa Maria, RS. E-mail: danielflores@ufsm.br.

** Bacharel em Arquivologia pela Universidade Federal de Santa Maria (UFSM). Endereço: Rua das Acáceas, 340, Complemento Pró-Moradia II, Caiçara, CEP 96540-000, Agudo, RS. E-mail: henrique.gralha@gmail.com.
} 
preservação digital com a gestão do conhecimento, uma questão que ainda é pouco discutida no âmbito da preservação de documentos arquivísticos digitais.

Palavras-chave: Arquivologia; Documento Arquivístico Digital; Preservação Digital; Encapsulamento; Gestão do Conhecimento.
Keywords: Archival Science; Digital Archival Document; Digital Preservation; Encapsulation; Knowledge Management.

\title{
INTRODUÇÃO
}

Devido à constante e acelerada evolução tecnológica, ocorreu a expansão do uso de software pela sociedade em geral. Dessa forma, obteve-se maior facilidade de acesso, variedade e volume de dados (DE SORDI, 2008). A revolução em meio digital já é considerada um caminho sem volta (INTERPARES, 2007).

A pesquisa e o ensino, assim como a sociedade em geral dependem da informação em meio digital. O avanço do conhecimento requer a preservação e da garantia de acesso a esses registros por tecnologias futuras. Além disso, deve-se garantir que os usuários interpretarão os dados corretamente (SAYÃO, 2010). A atividade de preservação se tornará ineficiente caso os futuros usuários não consigam interpretar corretamente os dados, as informações e os documentos preservados.

A tecnologia está presente em diversas áreas do conhecimento, acarretando fortes influências sobre as pessoas e organizações, tanto públicas quanto privadas, conforme Rosini e Palmisano (2003):

\begin{abstract}
Hoje em dia, inegavelmente, a tecnologia está presente na vida das pessoas. Os avanços da informática, dos computadores e de outras formas de tecnologia têm exercido efeito significativo também na vida das organizações. É difícil encontrar qualquer forma de organização ou de processo organizacional que não tenha sido alterado por novas tecnologias (ROSINI; PALMISANO, 2003, p. 9).
\end{abstract}

Os constantes avanços das tecnologias da informação também ocasionaram mudanças no principal objeto de estudo da arquivologia, o documento arquivístico (RONDINELLI, 2005). De maneira geral, com o advento do documento digital, surgiram novas abordagens para a gestão, a preservação e o acesso a documentos arquivísticos. Considerando que documentos arquivísticos digitais, dotados de valor histórico e informativo, começaram a ser produzidos exclusivamente em meio digital, surgiu a necessidade de preservar o patrimônio digital.

No âmbito da preservação digital, há uma série de estratégias como, por exemplo, a migração, a emulação, o encapsulamento, a preservação de tecnologia, a pedra de Rosetta digital e o refrescamento. Diversos autores apontam que cada estratégia será mais indicada em um determinado contexto de aplicação. Além disso, será preciso usá-las em conjunto para contemplar documentos digitais de várias naturezas e formatos.

Este artigo tem por objetivo realizar uma reflexão sobre as estratégias de encapsulamento, discutindo a sua aplicabilidade nos acervos, bem como o seu uso em conjunto com outras estratégias. $O$ método para realizar esta reflexão consiste 
no levantamento bibliográfico de materiais previamente publicados. Dessa forma, os dados coletados são analisados de forma qualitativa e sintetizados.

\section{DIMENSÕES DO ESTUDO}

De início, procede-se à contextualização do documento arquivístico digital. Posteriormente, apresentam-se os fundamentos de preservação digital. E, por fim, definem-se a as estratégias de encapsulamento.

\section{DOCUMENTO ARQUIVÍSTICO DIGITAL}

Inicialmente, a informação registrada em meio digital depende de um aparato tecnológico para que seja corretamente interpretada (SAYÃO, 2010). Quando se trata de documento digital, pode-se dizer que este é acessado e interpretado por meio de um sistema computacional (CONARQ, 2011; 2012), armazenado em suporte magnético, óptico ou óptico-magnético, composto por uma sequência de bits que é lida indiretamente por plataformas de hardware e software (INNARELLI, 2012a). De tal forma que um documento digital para se tornar arquivístico deverá ser produzido ou recebido por uma atividade orgânica (CONARQ, 2011; 2012).

A demanda por registros de natureza digital, e a sua consequente incorporação à arquivologia, transformou a sua forma de representação. Assim, "o documento se transformou, então, de objeto físico em objeto conceitual, controlado por metadados que combinam virtualmente conteúdo, contexto e estrutura" (FONSECA, 2005, p. 63). Deve-se ressaltar que por trás do objeto conceitual visualizado, existe um contexto tecnológico que permite a reprodução do documento. Conforme palavras de Rondinelli (2013):

[...] um documento digital, arquivístico ou não, exibido numa tela de computador, muda completamente a partir do momento em que o "salvamos" ou "fechamos". Isto porque, nesse momento, o documento deixa de ser compreensível aos olhos humanos para se transformar numa cadeia de bits (bits strings). [...] não é possível manter um documento digital exatamente como o vemos, a não ser que o imprimamos - e nesse caso ele deixaria de ser digital. 0 que se pode manter é a capacidade de reproduzir o documento sempre que necessário (RONDINELLI, 2013, p. 241).

A informação em meio digital não possui a relativa estabilidade dos registros em suporte físico (MÁRDERO ARELLANO; ANDRADE, 2006). Tal fragilidade dos documentos digitais pode estar na obsolescência tecnológica, na complexidade e nos custos e preservação em longo prazo (MÁRDERO ARELLANO, 2008). Desse modo, as complexidades e especificidades dos documentos digitais, atreladas ao aparato tecnológico necessário para sua representação, apresentam uma ruptura com relação ao modelo clássico de preservação de documentos arquivísticos, segundo Fonseca (2005):

A preservação não mais será voltada para a restauração, conservação e guarda adequada dos documentos físicos; ao contrário, seu principal objetivo será a migração e emulação constantes dos conceitos e inter-relações que agora definem os documentos eletrônicos para novos softwares. O importante, agora, é a preservação de conteúdos (FONSECA, 2005, p. 64). 
Ao se tratar de documentos em meio digital, os seus aparatos tecnológicos composto de hardware, software e suporte - são perfeitamente separáveis. De maneira geral, a informação registrada em meio digital é volátil, e por isso deverá ser transferida periodicamente.

\title{
PRESERVAÇÃO DIGITAL
}

A preservação digital consiste na atividade em garantir o acesso em longo prazo à informação digital autêntica, de forma que possa ser interpretada pelos usuários em uma plataforma tecnológica futura. A preservação digital é responsável pela comunicação entre produtores e pesquisadores, além do espaço e do tempo (FERREIRA, 2006).

Em se tratando de documentos digitais, a sua preservação "dependerá principalmente da solução tecnológica adotada e dos custos que ela envolve" (MÁRDERO ARELLANO, 2004, p. 15). Logo, percebe-se a importância de um planejamento, definindo-se, assim, a infraestrutura necessária para as atividades de preservação. Santos (2012) chama a atenção para um planejamento da preservação de documentos arquivísticos digitais:

\begin{abstract}
É imprescindível que a preservação dos documentos arquivísticos digitais se inicie no ato de criação do documento, ou mesmo antes. Isso porque deve contemplar o planejamento quanto às potencialidades das tecnologias de informação e comunicação envolvidas e procedimentos necessários à conformidade legal e normativa institucional dos documentos produzidos, aí incluídos os sistemas informatizados que gerenciarão esses documentos (SANTOS, 2012, p. 118).
\end{abstract}

As estratégias de preservação escolhidas devem se desenvolver e se adaptar às mudanças contínuas das tecnologias, caso contrário a "solução", ao se tornar obsoleta, será parte do problema (THIBODEAU, 2002). Tal fato reforça a necessidade de maiores discussões acerca das estratégias de preservação digital, pois muito se fala na importância da preservação digital, mas poucas vezes as estratégias e suas aplicabilidades são abordadas.

\section{ESTRATÉGIAS DE ENCAPSULAMENTO}

As estratégias de encapsulamento estão entre as mais citadas pelos autores da preservação digital. Essa técnica concentra-se na preservação do objeto lógico, permitindo assim manter as funcionalidades dos objetos digitais, pois não altera a sua estrutura.

Por meio dessa técnica, mantém-se o objeto digital original inalterado até que o acesso ao material seja requerido. Quando solicitado, o objeto digital original deverá ser tratado para tornar o acesso possível (GRÁCIO; FADEL, 2010).

O encapsulamento agrupa as informações referentes aos suportes de armazenamento, e a descrição do contexto tecnológico de hardware e software necessários para a correta interpretação dos objetos digitais. As informações são reunidas em um pacote onde serão inseridas as aplicações utilizadas durante o ciclo de vida dos documentos digitais, inclusive o software utilizado na sua criação (MÁRDERO ARELLANO, 2004; SARAMAGO, 2004). Dessa forma, a informação reunida possibilitará a recuperação do documento digital. 
Em linhas gerais, o encapsulamento reúne os componentes dos documentos digitais e até mesmo os softwares necessários para a sua correta interpretação. O material reunido é preservado em seu formato original até o momento em que o acesso seja solicitado.

\title{
ANÁLISE DAS ESTRATÉGIAS DE ENCAPSULAMENTO
}

Os ciclos de obsolescência das tecnologias estão cada vez mais curtos, por isso a recuperação dos documentos torna-se mais improvável. Considerando-se a necessidade de se desenvolver um emulador ou conversor, além do custo elevado para a implementação das estratégias de preservação de tecnologia em longo prazo, pode-se dizer que o encapsulamento será, em um primeiro momento, o procedimento mais viável. Com essa estratégia, será possível recuperar os documentos digitas em um futuro ainda indefinido.

\begin{abstract}
Vale ressaltar que um documento digital não é uma unidade simples, mas sim composto por um conjunto de componentes digitais que definem sua estrutura, tipo, tamanho e cores das fontes, existência de imagens etc. Alguns desses componentes (como os tipos de fonte ou imagens) estão presentes no ambiente de produção, mas não são, obrigatoriamente, carregados junto com o documento. Assim, é aconselhável o uso de formatos que encapsulem todos os componentes digitais, de modo a garantir que o documento tenha o máximo de independência do ambiente tecnológico em que foi criado (SANTOS, 2012, p. 121).
\end{abstract}

A correta interpretação de um documento digital dependerá da incorporação de todos os seus componentes digitais. Ao se encapsular toda a informação necessária para interpretar o documento digital, será possível assegurar-lhe uma apresentação fidedigna, garantindo tanto a integridade quanto a autenticidade.

\section{APLICAÇÃO GENÉRICA}

Há diversas alternativas para recriar o comportamento de um software qualquer. Mesmo assim, para executá-lo é necessário salvá-lo juntamente com os componentes do documento e todos os outros softwares necessários para interpretar o documento digital. Embora seja uma tarefa difícil, é teoricamente viável. É comum a guarda e a distribuição de documentos digitais juntamente com o software adequado para visualização e, por vezes, até mesmo uma cópia da versão apropriada do sistema operacional necessário para executar o software. Essa é muitas vezes a única maneira de assegurar que o usuário poderá interpretar corretamente o documento, considerando-se que o hardware necessário está disponível (ROTHENBERG, 1999).

Ao reunir todos os componentes do documento digital, aumentam as chances de sua recuperação, seja por meio da estratégia de encapsulamento ou então, por intermédio de estratégias de migração, emulação e outras que poderão surgir posteriormente. Além das perspectivas futuras, deve-se considerar que o encapsulamento demanda maior espaço lógico para armazenamento. Isso se deve à incorporação das informações necessárias para a sua correta interpretação, das quais não há como prever o espaço necessário em razão das particularidades de cada documento. 
É possível que a demanda por maior espaço de armazenamento dificulte a implementação de estratégias de encapsulamento, tornando-as até mesmo inviáveis, pois elas podem exigir a utilização de diversos documentos digitais, com os respectivos componentes, metadados e software necessários para interpretar os documentos e os próprios sistemas operacionais requeridos para instalá-los. Dessa forma, o tamanho e a diversidade dos formatos de arquivo são fatores que aumentarão a complexidade dos procedimentos de preservação digital, pois irão demandar o encapsulamento de mais software e sistemas operacionais. Existe, ainda, o risco de que com a obsolescência de hardware específico para a correta interpretação, a eficácia dessas estratégias seja contestada.

A disponibilidade e a racionalidade no uso de recursos são componentes-chave para todas as estratégias de preservação digital, mas em se tratando de encapsulamento, estudos devem ser realizados a fim de se verificar as tendências em termos de obsolescência tecnológica. Tais iniciativas se justificam pelo fato de que não se pode encapsular tudo. Em outras palavras, o encapsulamento de software interpretador juntamente com o sistema operacional muitas vezes não poderá ser aplicado para todos os documentos, pois seriam gastos muitos recursos para aquisição de espaço lógico. Além disso, não seria racional ocupar esse espaço encapsulando softwares interpretadores e sistemas operacionais, quando se deseja preservar documentos digitais com ampla utilização global ou padrões de preservação.

Aprofundando a questão citada anteriormente, conclui-se que não há necessidade de reunir o software interpretador e o sistema operacional para a representação de um documento que não se encontre sob o risco de obsolescência. Tanto os formatos recomendados para a preservação quanto os formatos utilizados em larga escala são interpretados por softwares e sistemas operacionais facilmente acessíveis no presente. Desse modo, entende-se que para esses tipos de documentos, precisam ser encapsulados os seus componentes digitais, bem como as informações que irão auxiliar a sua correta interpretação por outros usuários no futuro. Caso o software interpretador e/ou sistema operacional considerados necessários para a correta interpretação do documento venham a se tornar obsoletos, devem ser encapsulados: documento, software e sistema operacional.

As vantagens mais significativas do encapsulamento estão na sua aplicabilidade, já que podem ser encapsulados documentos de todas as naturezas e formatos. Assim, o encapsulamento se configura como uma estratégia pertinente para o plano de preservação digital, podendo, ainda, auxiliar na execução de outras estratégias.

\section{APLICAÇÃO ESPECÍFICA: DOCUMENTOS DE TEXTO}

As estratégias de encapsulamento têm como fundamento reunir os componentes digitais necessários para a representação dos documentos. Em se tratando de documentos textuais, pode-se dizer que as fontes utilizadas na escrita são fundamentais para sua representação. Deve-se se ressaltar que os componentes digitais encapsulados podem ser armazenados como objetos digitais separados ou inseridos em um único objeto.

Método de encapsulamento utilizado para documentos textuais, o PDF/A - também conhecido como "PDF arquivístico" - é capaz de reunir os componentes digitais de documentos textuais em um único objeto. O PDF/A consiste em um formato de 
arquivo estandardizado que agrega forma fixa ${ }^{1}$ e conteúdo estável, ${ }^{2}$ os quais são componentes da fixidez preconizada pela diplomática contemporânea.

Deve-se destacar que há diferentes versões para o PDF/A. Discute-se agora o PDF/A1, que não permite imagens com transparências ou compressão, nem scripts ou arquivos executáveis embutidos. Entretanto, ele permite anexar um pacote de informação ao documento original, reunindo os respectivos metadados e componentes necessários para sua correta representação.

\begin{abstract}
A fixidez é uma das características do documento arquivístico que mais impactam na percepção humana quanto à sua confiabilidade. Talvez por isso, tem-se orientado a escolha do formato PDF-A1 para a produção de documentos arquivísticos digitais, por sua baixa exigência de recursos tecnológicos para sua apresentação e sua perspectiva de perenidade (SANTOS, 2012, p. 120).
\end{abstract}

O encapsulamento de documentos textuais em PDF/A1 gera pacotes de informação que incorporam as fontes utilizadas no documento. Dessa forma, minimizam-se as dificuldades de leitura por ausência de fontes específicas. Além disso, o PDF/A1 garante a forma fixa e o conteúdo estável do documento. O documento arquivístico digital será sempre de natureza textual, e seu conteúdo permanecerá inalterado, não permitindo nem mesmo a inserção de objetos digitais como anexos a ele.

Há de se ressaltar a relevância do formato PDF/A1 por elevar a maturidade na preservação digital de documentos textuais.

O PDF/A1 se configura, assim, como uma segunda alternativa para a preservação de documentos de natureza textual, juntamente com os formatos do Open Document Format (ODF). ${ }^{3}$ Além disso, tanto o PDF/A1 quanto o ODF são padrões de direito, ou seja, têm suas especificidades documentadas e licenças de uso que permitem a reconstrução do formato. A vantagem do PDF/A1 sobre o ODF pode ser destacada sobre dois aspectos principais: o PDF/A1 não permite, por exemplo, alterações de conteúdo, comentários, nem inserção de anexos; e o PDF/A1 encapsula as fontes no próprio documento, garantindo-lhe a fixidez arquivística.

Com base no formato proprietário PDF, considerado internacionalmente como um padrão de fato devido à sua ampla utilização, criou-se assim o PDF/A, formato aberto que contempla requisitos arquivísticos de fixidez. O PDF/A1, por sua vez, constitui o padrão ISO 19005-1: 2005, ideal para a preservação de documentos arquivísticos digitais em longo prazo.

De maneira mais geral, Thomas (2006) realça as vantagens da família PDF/A, apresentando-a como uma possível tendência no campo arquivístico:

Com o PDF/A, as instituições arquivísticas poderão intercambiar seus conteúdos digitais com muita facilidade, pois o formato possui uma série de recursos que facilitam essa tarefa, tais como, suporte interno a metadados em XML, imagens supercomprimidas, imagens pesquisáveis pelo conteúdo, conexões de hipertexto etc.

\footnotetext{
${ }^{1}$ Documento arquivístico que assegura a mesma apresentação quando recuperado (INTERPARES, 2007).

${ }^{2}$ Documento arquivístico que torna imutáveis a informação e os dados nele contidos, exigindo que eventuais alterações sejam feitas por meio do acréscimo de atualizações ou da produção de uma nova versão (INTERPARES, 2007).

${ }^{3}$ NBR ISO 26300: 2008.
} 
A expectativa é de que o formato PDF/A torne-se preferencial em projetos nos quais a permanência dos documentos seja fundamental, substituindo definitivamente os formatos de escritório proprietários (THOMAZ, 2006, p. 127).

Embora muito eficiente para documentos textuais, o PDF/A não poderá ser aplicado para outros objetos digitais, como softwares e objetos interativos. Entretanto, o PDF/A já desponta em algumas iniciativas de preservação digital.

No protótipo inicial do Repositório de Objetos Digitais Autênticos (RODA), o PDF/A foi definido como o padrão para preservar documentos com texto estruturado, que poderão conter tabelas e imagens fixas, mantendo o mesmo aspecto e paginação do documento original (RAMALHO et al., 2007).

Em linhas gerais, o encapsulamento é uma estratégia fundamental para o plano de preservação, e pode ser aplicado a todos os tipos de documentos. Por outro lado, os procedimentos utilizando PDF/A são os ideais para documentos textuais. Além disso, o encapsulamento poderá potencializar a eficácia de outras estratégias, como a emulação e a migração.

\section{SINCRONIZANDO ESTRATÉGIAS DE PRESERVAÇÃO DIGITAL}

Mesmo encapsulando os componentes digitais do documento, seus metadados, o software interpretador e o sistema operacional, não há garantia real de recuperação dos documentos encapsulados. Além de reunir toda a informação necessária para a correta interpretação dos documentos digitais, as estratégias de encapsulamento podem servir de auxílio à emulação e à migração.

Dessa forma, pode-se trabalhar com a possibilidade que no futuro exista uma tecnologia capaz de recuperar os documentos digitais encapsulados. Logo, o encapsulamento fornecerá uma base de conhecimento e materiais de relevância ímpar para o desenvolvimento de conversores, emuladores e visualizadores.

\section{EMULADORES, CONVERSORES E VISUALIZADORES}

O desenvolvimento de emuladores, conversores e visualizadores está entre as principais finalidades das estratégias de encapsulamento. Além deles, deve-se apontar "o novo", pois no futuro podem ser desenvolvidas novas tecnologias, e consequentemente, novas estratégias de preservação digital.

Inicialmente, tendo em vista que as estratégias de encapsulamento podem ser sincronizadas com as de emulação, levam-se em consideração as especificações do emulador a ser usado e o histórico dos objetos digitais (MÁRDERO ARELLANO, 2008). Sendo assim, é importante que informações relevantes sejam coletadas durante o encapsulamento dos materiais, para que no futuro seja possível desenvolver um emulador ou mesmo utilizar algum já existente.

Durante o encapsulamento, devem-se descrever os requisitos necessários aos emuladores, com o objetivo de gerar compatibilidade de hardware e software. Ao contemplar esses requisitos, a plataforma emulada conseguirá interpretar corretamente os documentos digitais anteriormente encapsulados. Desse modo, é possível sincronizar o encapsulamento com as estratégias de emulação, descrevendo os requisitos necessários para os emuladores. 
De certa forma, não há como definir o valor de determinados objetos digitais. Vários anos podem se passar até que o interesse por uma determinada coleção de objetos seja manifestado (HEMINGER; ROBERTSON, 2000). Considerando essa questão, as estratégias de encapsulamento podem proporcionar certa economia de recursos para as instituições responsáveis pela preservação em longo prazo. Inicialmente, os documentos digitais seriam encapsulados e os procedimentos para o seu tratamento seriam realizados quando os usuários solicitassem o acesso. A economia de recursos seria considerável, visto que as tecnologias utilizadas para acesso vão se tornando obsoletas, a solução se torna o problema, gerando a necessidade de uma nova atualização. Ao proceder ao encapsulamento, eliminam-se os esforços para emular e migrar documentos que não estão sendo acessados. Desse modo, os documentos que, no momento, não possuam interesse para nenhuma comunidade deixam de consumir recursos da instituição.

Da mesma forma que o encapsulamento auxilia as estratégias de emulação, também poderá contribuir para a migração de versões e formatos. Nesse caso, os documentos digitais que foram encapsulados com seus componentes digitais servirão de base para o desenvolvimento de conversores. Acredita-se que as informações fornecidas pelos metadados - e pelos demais componentes digitais encapsulados -, serão capazes de fornecer o conhecimento necessário a fim que os formatos obsoletos sejam corretamente convertidos para formatos compatíveis com as tecnologias atuais. Além disso, Rothenberg (1999) comenta sobre a necessidade de se ter extremo cuidado com relação à migração dos documentos digitais e do seu software interpretador. Seus fluxos de bits não podem ser modificados de um modo que afete sua interpretação, pois os softwares interpretadores e os objetos digitais podem ser corrompidos pela mínima mudança.

As questões apresentadas reforçam a necessidade de preservar o documento original, possibilitando a reversão do procedimento em caso de um resultado indesejado. Recomenda-se que um plano de preservação contemple a manutenção de dois objetos digitais em paralelo: o objeto original e do objeto de preservação. $O$ objeto original é mantido sem manipulações, já sobre o objeto de preservação haverá maior liberdade para implementar estratégias. Caso ocorra algum erro no procedimento, tem-se o objeto digital em seu formato original.

Contudo, será mais difícil recuperar documentos digitais que tenham sido criados em versões de software proprietário ou fechado. Isso implica em uma série de restrições quanto ao acesso à estrutura interna dos documentos e de seus componentes digitais. Há de se ressaltar que tanto a restrição de acesso ao código fonte quanto a necessidade de aquisição de licenças de uso implicam, respectivamente, a falta de compreensão da estrutura e custos mais elevados para a preservação dos documentos digitais. Considerando esses aspectos, o uso de software proprietário ou fechado dificulta a recuperação dos documentos digitais em longo prazo, seja aumentando os custos, seja dificultando o desenvolvimento de emuladores, conversores e visualizadores.

Por vezes, não será viável o armazenamento de todos os componentes necessários para a correta interpretação dos documentos digitais - isso se deve à demanda por espaço lógico e âs restrições impostas pelo software proprietário de código fechado. De maneira geral, pode-se encapsular o documento digital com seus componentes digitas, em especial os seus metadados, os quais fornecerão uma informação descritiva relevante. Assim, o sistema operacional, que demanda maior espaço de armazenamento, e o software interpretador de uso restrito podem ser eliminados do encapsulamento, mas devem ter seu desempenho devidamente descrito, o que pode 
viabilizar o desenvolvimento de uma tecnologia capaz de interpretar o documento digital corretamente.

Não há a necessidade de se usar o software que originou o documento para visualizálo, pode-se optar por descrever o seu comportamento de forma independente do sistema. Ou seja, a descrição não é incorporada ao software que originou o documento, e sim a uma base de conhecimento independente. Dessa forma, as gerações futuras poderiam interpretar a descrição do software salva, a fim de recriar o seu comportamento e, finalmente, ler o documento (ROTHENBERG, 1999). Com essa abordagem, será possível desenvolver softwares que possibilitem a visualização do documento descrito. Acredita-se que a partir do conhecimento de suas especificidades, será possível recriar o ambiente tecnológico. Assim, além de visualizadores, poderão ser desenvolvidos emuladores que satisfaçam as especificidades que foram descritas.

\section{GESTÃO DO CONHECIMENTO}

O encapsulamento permite a manutenção dos documentos digitais em formato original. Entretanto, para que essa estratégia seja bem-sucedida, é necessário que o documento digital contenha um conjunto de instruções que permitam interpretar os seus componentes digitais, bem como o seu conteúdo (LOPES, 2008). A necessidade de se manter uma base de informações relacionadas ao documento encapsulado chama a atenção para a relação existente entre as práticas de preservação digital e a gestão do conhecimento.

Santos (2007) apresenta uma breve definição:

[...] entende-se por gestão do conhecimento o conjunto de processo, práticas e procedimentos que visam identificar, registrar e gerenciar o conhecimento das pessoas de forma a garantir sua utilização, difusão e aplicação no âmbito institucional (SANTOS, 2007, p. 191).

Conforme apontam Silva Filho e Silva (2005), existem diferentes tipos de conhecimento que são classificados como conhecimento explícito e conhecimento tácito. Para o conhecimento explícito, apresentam a seguinte definição:

[...] é um conhecimento útil, tal como um dado ou uma informação. Esse tipo de conhecimento está registrado e pode ser facilmente processado, armazenado e transmitido. $\mathrm{O}$ conhecimento explícito pode ser transmitido, por exemplo, por meio de aulas, livros ou manuais de instruções (SILVA FILHO; SILVA, p. 28, 2005).

Já "o conhecimento tácito possui uma qualidade pessoal” (SILVA FILHO; SILVA, p. 28, 2005). Ou seja, é aquele conhecimento que está restrito ao indivíduo e ainda não foi registrado. Rosini e Palmisano (2003) comentam sobre o processo de transformação do conhecimento:

Dar visibilidade ao conhecimento na organização, transformar o conhecimento tácito em explícito é um dos grandes desafios fundamentais da gestão do conhecimento, em que é importante haver maturidade entre a distinção e percepção e a transferência de conhecimento (ROSINI; PALMISANO, p. 139-140, 2003). 
A definição de conhecimento explícito se assemelha às atividades de descrição dos componentes digitais do documento. É importante salientar que as especificações dos documentos encapsulados devem estar explícitas, de modo que possam ser interpretadas corretamente por outros usuários no futuro.

\begin{abstract}
O conhecimento quando preservado a partir dos documentos arquivísticos digitais e seus processos informatizados permitirá seu compartilhamento no futuro. Compartilhamento que garantirá a perpetuação de conhecimento explícito seja qual for à tecnologia utilizada pelas próximas gerações (INNARELLI, 2012b, p. 62).
\end{abstract}

O conhecimento das plataformas do passado, quando encapsulado e preservado de forma compreensível, poderá servir de base para o desenvolvimento de tecnologias capazes de recuperar os documentos. De maneira geral, as práticas de preservação digital poderão ser auxiliadas como um todo pelas atividades de gestão do conhecimento. Adiciona-se aqui um destaque para as estratégias de encapsulamento e a sua possível sincronização com a emulação, a migração e o desenvolvimento de tecnologias futuras.

Eventualmente, a ciência da informação pode desenvolver modelos de processamento de informação humana e computação que permitirão digitalizar documentos para serem armazenados na forma independente do sistema, mas isso não acontecerá em tempo de salvar a atual geração de documentos (ROTHENBERG, 1999). É preciso trabalhar com as soluções que já estão consolidadas, mas, ao mesmo tempo, devem-se explorar as alternativas existentes.

\title{
CONCLUSÃO
}

Este artigo permite vislumbrar uma relação indissociável entre o documento arquivístico digital, as estratégias de preservação digital e a gestão do conhecimento. Tal relação é estabelecida ao se aprofundar a análise das estratégias de encapsulamento de documentos arquivísticos digitais em longo prazo.

Os documentos arquivísticos digitais possuem um contexto tecnológico necessário para a sua correta interpretação. Desse modo, é preciso conhecer, descrever e preservar os componentes necessários, bem como registrar o conhecimento. Nesse contexto, as estratégias de encapsulamento exercem um papel fundamental, considerando-se a sua abordagem no sentido de reunir todos os componentes e informações necessárias para a correta interpretação dos documentos digitais.

As estratégias de encapsulamento podem ser aplicadas de maneira genérica, contemplando-se, assim, documentos de todas as naturezas e formatos. Esses são fatores que reforçam a implementação dessa estratégia nos acervos arquivísticos, embora não possa ser considerada a solução para todos os problemas de obsolescência tecnológica. Todavia, as estratégias de encapsulamento podem auxiliar tanto a migração quanto a emulação, e caso essas abordagens não satisfaçam as expectativas, tais estratégias abrem ainda a possibilidade de que as tecnologias do futuro sejam capazes de recuperar os documentos. Dessa forma, os requisitos para possibilitar essa recuperação são a manutenção dos documentos com seus componentes digitais, juntamente com uma base de conhecimento que descreva o seu contexto tecnológico de hardware e software.

Além das aplicações genéricas, o uso do PDF/A se configura como um importante padrão ISO, fornecendo uma alternativa aos formatos ODF. Deve-se destacar que o 
PDF/A possui diversas versões destinadas a áreas diferentes, por isso é necessário usar a versão para arquivamento, o PDF/A1. Essa versão possui uma série de restrições para funcionalidades que aumentam a vulnerabilidade do documento arquivístico digital, ou seja, elas são positivas quando se quer preservar documentos digitais autênticos de maneira confiável.

De maneira geral, a preservação digital como um todo deve se aproximar da gestão do conhecimento, registrando todo o conhecimento que está relacionado com as práticas de preservação. Destaca-se que esse conhecimento deve ser documentado e preservado de forma acessível, fornecendo informações que irão colaborar para a preservação de outros documentos. Logo, o documento arquivístico, a preservação digital e a gestão do conhecimento formam um ciclo de retroalimentação que poderá se estender e possibilitar o acesso em longo prazo.

Artigo recebido em 27/01/2015 e aprovado em 16/03/2015.

\section{REFERÊNCIAS}

CONSELHO NACIONAL DE ARQUIVOS - Conarq (Brasil). Câmara Técnica de documentos eletrônicos. e-ARQ Brasil: Modelo de Requisitos para Sistemas Informatizados de Gestão Arquivística de Documentos. Rio de Janeiro: Arquivo Nacional, 2011. Disponível em: <http://www.conarq.arquivonacional.gov.br/media/publicacoes/earq/conarq_earqbra sil_model_requisitos_2009.pdf >. Acesso em: 5 ago. 2014.

. Câmara Técnica de documentos eletrônicos. Diretrizes para a presunção de autenticidade de documentos arquivísticos digitais. Rio de Janeiro: Arquivo Nacional, 2012. Disponível em: <http://www.conarq.arquivonacional.gov.br/media/diretrizes_presuncao_autenticida de_publicada.pdf $>$. Acesso em: 20 jun. 2014.

DE SORDI, José Osvaldo. Administração da informação: fundamentos e práticas para uma nova gestão do conhecimento. São Paulo: Saraiva, 2008.

FERREIRA, Miguel. Introdução à preservação digital: conceitos, estratégias e atuais consensos. Guimarães: Escola de Engenharia da Universidade do Minho, 2006. Disponível

em: <https://repositorium.sdum.uminho.pt/bitstream/1822/5820/1/livro.pdf >. Acesso em: 2 ago. 2014.

FONSECA, Maria Odila Kahl. Arquivologia e ciência da informação. Rio de Janeiro: Ed. FGV, 2005.

GRÁCIO, José Carlos Abbud; FADEL, Bárbara. Estratégias de preservação digital. In: VALENTIM, Marta. (Org.). Gestão, mediação e uso da informação. São Paulo: Ed. Unesp: Cultura Acadêmica, 2010. Disponível em: <http://books.scielo.org>. Acesso em: 1 Dez. 2014.

HEMINGER, Alan R.; ROBERTSON, Steven B. The digital Rosetta Stone: a model for maintaining long-term access to static digital documents. Communications of the Association for Information Systems (AIS), v. 3, article 2, Feb. 2000. Disponível em: $<$ http://dl.acm.org/citation.cfm?id=374497\&dl=ACM\&coll=DL\&CFID=514415141\&CFTOK $\mathrm{EN}=70364297>$. Acesso em: 24 Set. 2014. 
INNARELLI, Humberto Celeste. Instrumenta 2: preservação de documentos digitais. São Paulo: Associação dos Arquivistas de São Paulo, 2012a.

- Preservação digital: a gestão e a preservação do conhecimento explícito digital em instituições arquivísticas. InCID: revista de Ciência da Informação e Documentação, Ribeirão Preto, v. 3, n. 2, p. 48-63, jul./dez. 2012b. Disponível em: <http://www.revistas.usp.br/incid/article/view/48653>. Acesso em: 28 Dez. 2014.

INTERPARES 2 PROJECT. Diretrizes do produtor. A elaboração e a manutenção de materiais digitais: diretrizes para indivíduos. Tradução: Arquivo Nacional e Câmara dos Deputados. 2002-2007. (TEAM Brasil). Disponível em: $<$ http://www.interpares.org/ip2/display_file.cfm?doc=ip2_creator_guidelines_booklet --portuguese.pdf $>$. Acesso em: 9 Ago. 2014.

LOPES, Vitor. Preservação digital. Guimarães: Universidade do Minho, 2008. Disponível em: <http://www.vitorlopes.com/Trabalhos/Preservacao_DigitalVitor_Lopes.pdf>. Acesso em: 28 Ago. 2012.

MÁRDERO ARELLANO, Miguel Ángel. Critérios para a preservação digital da informação científica. 354 p. Tese (Doutorado em Ciência da Informação) Departamento de Ciência da Informação, Universidade Federal de Brasília, 2008. Disponível

em: <http://bdtd.bce.unb.br/tedesimplificado/tde_busca/arquivo.php?codArquivo=4547>. Acesso em: 15 jun. 2014.

. Preservação de documentos digitais. Ciência da Informação, Brasília, v. 33, n. 2, p. 15-27, maio/ago. 2004. Disponível em: <http://revista.ibict.br/ciinf/index.php/ciinf/article/view/305/1452>. Acesso em: 25 jul. 2014.

MÁRDERO ARELLANO, Miguel Ángel; ANDRADE, Ricardo Sodré. Preservação digital e os profissionais da informação. DataGramaZero: revista de Ciência da Informação, v.7 n. 5, out. 2006. Disponível em: <http://www.dgz.org.br/outo6/Art_05.htm>. Acesso em: 7 Set. 2014.

RAMALHO, José Carlos et al. XML e preservação digital. Lisboa, 2007. Disponível em: <http://repositorium.sdum.uminho.pt/handle/1822/6224>. Acesso em: 20 Ago. 2014.

ROCHA, Claudia Lacombe; SILVA, Margareth da. Padrões para garantir a preservação e o acesso aos documentos digitais. Acervo, Rio de Janeiro, v. 20, n, 1-2, p. 113-124, jan. dez. 2007. Disponível em: <http://www.revistaacervo.an.gov.br/seer/index.php/info/article/view/142>. Acesso em: 7 Set. 2014.

RONDINELLI, Rosely Curi. Gerenciamento arquivístico de documentos eletrônicos: uma abordagem teórica da diplomática arquivística contemporânea. 4. ed. Rio de Janeiro: Ed. FGV, 2005.

. O documento arquivístico ante a realidade digital: uma revisão conceitual necessária. Rio de janeiro: Ed. FGV, 2013.

ROSINI, Alessandro Marco; PALMISANO, Angelo. Administração de sistemas de informação e a gestão do conhecimento. São Paulo: Pioneira Thomson Learning, 2003.

ROTHENBERG, Jeff. Avoiding technological quicksand: finding a viable technical foundation for digital preservation. Commission on Preservation and Access and Council on Library and Information Resources: a report to the Council on Library and 
Information Resources. Washington, DC, 1999. Disponível em: <http://www.clir.org/pubs/reports/rothenberg/pub77.pdf>. Acesso em: 24 Set. 2014.

SANTOS, Vanderlei Batista dos. A prática arquivística em tempos de gestão do conhecimento. In: SANTOS, Vanderlei Batista dos. Arquivística: temas contemporâneos. Brasília: Senac, 2007. p. 175-223.

- Preservação de documentos arquivísticos digitais. Ciência da Informação, Brasília, v. 41 n. 1, p.114-126, jan./abr. 2012. Disponível em: <http://revista.ibict.br/index.php/ciinf/article/view/2110/1797>. Acesso em: 20 dez. 2014.

SARAMAGO, Maria de Lurdes. Metadados para preservação digital e aplicação do modelo OAIS. Actas do Congresso Nacional de Bibliotecários, Arquivistas e Documentalistas, Lisboa: Associação Portuguesa de Bibliotecários, Arquivistas e Documentalistas, n. 8, maio 2004. Nas encruzilhadas da informação e da cultura (re)inventar a profissão. Disponível em: <http://www.bad.pt/publicacoes/index.php/congressosbad/article/view/640/637>. Acesso em: 4 jul. 2014.

SAYÃO, Luís Fernando. Repositórios digitais confiáveis para a preservação de periódicos eletrônicos Científicos. Ponto de Acesso, Salvador, v. 4, n. 3, p. 68-94, dez. 2010. Disponível em: <http://www.portalseer.ufba.br/index.php/revistaici/article/view/4709/3565>. Acesso em: 8 ago. 2014.

SILVA FILHO, Cândido Ferreira da; SILVA, Lucas Frazão. Da aprendizagem à gestão do conhecimento. In: SILVA FILHO, Cândido Ferreira da; Lucas Frazão Silva (Org.). Tecnologia da informação para a gestão do conhecimento: teoria e estudos em organizações. Campinas: Alínea, 2005.

THIBODEAU, Kenneth. Overview of technological approaches to digital preservation and challenges in coming years, presented at the state of digital preservation: an international perspective. Washington, D.C: Council on Library and Information Resources, 2002. Disponível em: <http://www.clir.org/pubs/reports/pub107/thibodeau.html>. Acesso em: 19 ago. 2014.

THOMAZ, Kátia de Pádua. Gestão e preservação de documentos eletrônicos de arquivo: revisão de literatura - parte 2. Arquivística.net, Rio de Janeiro, v. 2, n.1, p.114131, jan./.jun. 2006. Disponível em: <www.brapci.ufpr.br/download.php?ddo=6733>. Acesso em: 7 set. 2014. 